\title{
Effects of Storage Temperature on Fruit Quality and Expression of Sucrose Phosphate Synthase and Acid Invertase Genes in Japanese Pear
}

\author{
Akihiro Itai $^{1 *}$, Ryusuke Hatanaka ${ }^{1}$, Hiroki Irie ${ }^{1}$ and Hideki Murayama ${ }^{2}$ \\ ${ }^{1}$ Faculty of Agriculture, Tottori University, Tottori 680-8553, Japan \\ ${ }^{2}$ Faculty of Agriculture, Yamagata University, Tsuruoka 997-8555, Japan
}

Japanese pear (Pyrus pyrifolia Nakai) 'Gold Nijisseiki' fruit were stored for 28 days at $0,4,10,15$, or $22^{\circ} \mathrm{C}$. The effects of storage temperature on sucrose metabolism and on the expression of genes for sucrosemetabolizing enzymes were investigated. Fruit firmness, skin color, and content of various sugars were affected by storage temperature. Fruit stored at $22^{\circ} \mathrm{C}$ underwent rapid fruit softening and skin color change. Fruit stored at 15 or $10^{\circ} \mathrm{C}$ had lower sucrose content and higher glucose and fructose content than those stored at 0 , 4 , or $22^{\circ} \mathrm{C}$. To investigate whether sucrose loss is related to changes in the expression of sucrose-metabolizing enzymes (vacuolar acid invertase: AIV; and sucrose phosphate synthase: SPS), we examined the expression of 3 genes during storage, namely, those encoding AIV (PpAIV1 and PpAIV2) and SPS (PpSPS1). Storage at 10 and $15^{\circ} \mathrm{C}$ increased the expression of $P p A I V 2$ within a week and that of $P p A I V 1$ in 14 days, while storage at 0 and $4^{\circ} \mathrm{C}$ delayed increased expression of $P p A I V 1$ and $P p A I V 2$ until after 28 days. Changes in the gene expression of sucrose-metabolizing enzymes were followed by delayed responses in sugar content.

Key Words: acid invertase, cold storage, Pyrus pyrifolia Nakai, sucrose metabolism.

\section{Introduction}

The composition and concentration of sugars are important components of fruit quality. In pear, sorbitol is the major translocation carbohydrate form of photosynthates (Bieleski, 1977; Loescher, 1987; Webb and Burley, 1962), and is converted into fructose and glucose by $\mathrm{NAD}^{+}$-dependent sorbitol dehydrogenase $(\mathrm{SDH})$ and sorbitol oxidase (SOX), respectively. Sucrose is then synthesized or degraded by the enzymes sucrose phosphate synthase (SPS), sucrose synthase (SS), and acid invertase (AIV) (Tanase and Yamaki, 2000; Yamaki and Moriguchi, 1989). For these reasons, sucrose, glucose, fructose, and sorbitol contents play a key role in determining the sweetness of Japanese pear (Pyrus pyrifolia Nakai) fruit (Kajiura et al., 1979), although there are large differences in sugar composition among cultivars (Moriguchi et al., 1992). Sucrose be-

Received; November 30, 2014. Accepted; February 22, 2015.

First Published Online in J-STAGE on April 8, 2015.

This work was supported in part by Grants-in-Aid from the Ministry of Education, Culture, Sports, Science and Technology of Japan (No. 20380021) and from the Japanese Society for the Promotion of Science (No. 24380022).

* Corresponding author (E-mail: itai@muses.tottori-u.ac.jp). gins to accumulate in fruit tissues in the maturing stage. Some cultivars such as 'Nijisseiki' and 'Chojuro' accumulate sucrose as over $50 \%$ of the neutral sugar in ripening fruit (Kajiura et al., 1979). The cultivar differences in the accumulation of sucrose are regulated by the activity of enzymes catabolizing sucrose (Moriguchi et al., 1992).

Because most of the reactions in fruit are biochemical and thus temperature-dependent, storage temperature is the primary factor affecting fruit freshness, shelf life, and quality. At higher temperature following harvest, European pear as well as other temperate fruits rapidly become yellow and overripe (Knee et al., 1983; Porrit, 1964). Although storage at low temperature is a common practice for retarding the softening of fruit, long periods of cold storage are known to alter the taste rating of pear (Beutel, 1990; Ke et al., 1991). In our previous study, storage at $4^{\circ} \mathrm{C}$ for longer than 1 month caused the accumulation of hexoses and a decrease in sucrose in Japanese pear (Itai and Tanahashi, 2008) due to up-regulation of invertase genes (PpAIV1) and downregulation of a SPS gene (PpSPS1). Moreover, the addition of treatment with 1-methylcyclopropene inhibited the accumulation of PpAIVI transcripts and the decline in PpSPS1 transcripts, resulting in delayed sucrose loss. 
However, it is unclear which storage temperatures specifically affect sucrose metabolism. Against this background, the present study aimed to determine the effect of 5 different storage temperatures on sucrose metabolism in Japanese pear fruit.

\section{Materials and Methods}

\section{Plant materials and treatment}

Over 300 fruit from 3 Japanese pear (Pyrus pyrifolia) 'Gold Nijisseiki' trees grown at a commercial orchard in Tottori, Tottori Prefecture, Japan, were used for the present experiments. Fruit were harvested on 3 September, 2009, 141 days after full bloom, which is the optimal commercial harvest date for 'Gold Nijisseiki'. Fruit were packed in ventilated commercial boxes $(\mathrm{W} \times \mathrm{D} \times \mathrm{H}: 500 \mathrm{~mm} \times 350 \mathrm{~mm} \times 275 \mathrm{~mm})$ and packed boxes of fruit were kept at 1 of 5 temperatures $\left(0,4,10,15\right.$, or $\left.22^{\circ} \mathrm{C}\right)$ for up to 28 days.

\section{Fruit quality assessments}

Ten fruit per treatment were sampled at $0,7,14$, and 28 days after harvest. Fruit color and flesh firmness of the 10 individual fruit were determined on opposite sides of each fruit. Flesh firmness was determined by using a rheometer (RT-3010D; Sun Scientific Co., Tokyo, Japan) to measure the force required to penetrate each peeled fruit to a depth of $1 \mathrm{~cm}$. Puncture tests were performed using an $8-\mathrm{mm}$ probe on a drill base with crosshead speed set at $50 \mathrm{~mm} \cdot \mathrm{min}^{-1}$. To quantify color, $\mathrm{L}^{*}, \mathrm{a}^{*}$, and $\mathrm{b}^{*}$ were assessed using a spectrophotometer (NF333; Nippon Denshoku Co., Tokyo, Japan) and recorded. Hue angle $\left(h^{\circ}\right)$ was calculated using arc$\tan \mathrm{b}^{*} / \mathrm{a}^{*}$ (McGuire, 1992). After these measurements, juice was collected from 2 fruit as replicates, and a total of 5 replicates were used for sugar composition analysis. A hand-operated garlic squeezer was used to extract juice from peeled fruit. Juice yield was approximately $70 \%$. Extracted juice was centrifuged at $20000 \times \mathrm{g}$ and $4^{\circ} \mathrm{C}$ for $15 \mathrm{~min}$. Supernatant was diluted with water and filtered with a $0.2-\mu \mathrm{m}$ filter unit (Millex-GN; Millipore, Bedford, MA, USA). A $20 \mu \mathrm{L}$ aliquot was injected into a high-pressure liquid chromatography system (L7470; Hitachi Koki Co., Tokyo, Japan) equipped with a refractive index detector (Model L7490; Hitachi Koki Co., Tokyo, Japan) and a ShodexAsahi pack SP0810 column (Showa Denko KK, Tokyo, Japan), with water used as the solvent at a flow rate of $1 \mathrm{~mL} \cdot \mathrm{min}^{-1}$ at $80^{\circ} \mathrm{C}$. Fresh tissue samples from the equatorial region of each fruit were also frozen in liquid nitrogen and stored at $-80^{\circ} \mathrm{C}$ until RNA extraction.

\section{RNA extraction and real-time quantitative RT-PCR}

Total RNA was extracted by the hot borate method (Wan and Wilkins, 1994). First-strand cDNA was synthesized from $1 \mu \mathrm{g}$ of total RNA from fruit using MMLV reverse transcriptase (ReverTra Ace; Toyobo, Tokyo, Japan). Expression levels were then analyzed using the Mini Opticon real-time polymerase chain reaction (PCR) system from Bio-Rad. Each sample was tested in duplicate in a 48-well plate (Bio-Rad, Hercules, CA, USA). The reaction mix ( $20 \mu \mathrm{L}$ final volume) consisted of $10 \mu \mathrm{L}$ of FastStart SYBR Green mix (Roche Applied Science, Mannheim, Germany), $1 \mu \mathrm{L}$ of each primer ( $200 \mathrm{nM}$ final concentration) described below, $2 \mu \mathrm{L}$ of $\mathrm{H}_{2} \mathrm{O}$, and $3 \mu \mathrm{L}$ of a $1 / 10$ dilution of the cDNA preparation. The absence of genomic DNA in RNA samples was checked by real-time PCR before cDNA synthesis (minus RT control). A blank (no template) control was incorporated in each assay. The thermocycling program consisted of initial holding at $95^{\circ} \mathrm{C}$ for $3 \mathrm{~min}$, followed by 40 cycles of $10 \mathrm{~s}$ at $95^{\circ} \mathrm{C}, 20 \mathrm{~s}$ at $60^{\circ} \mathrm{C}$, and $20 \mathrm{~s}$ at $72^{\circ} \mathrm{C}$. After completion of these cycles, melting-curve data were collected to assess PCR specificity, contamination, and the absence of primer dimers. Furthermore, PCR products were checked by electrophoresis on a $2 \%$ agarose gel and staining with ethidium bromide. The threshold cycle $(\mathrm{Ct})$ values were measured using the gene expression module of the BIORAD CFX Manager software by the $\triangle \Delta$ Cq method.

The PpSPS1 gene was amplified from cDNA by PCR using the following oligonucleotide primers: sense 5'TGGACTTAGATTACCGTTCGCA-3' and antisense 5'GGGGAATCAGTGCTGGATCT-3', based on the PpSPS1 sequence (Itai and Tanahashi, 2008). The primers for PpAIV1 and PpAIV2 were designed as follows (Itai and Tanahashi, 2008). The sense primer was 5'GCTGGTTGATCATTCGATCGT-3', while the antisense primer was 5'-GGGTAGCCTTGACATTCA CTC-3' for PpAIV1. The sense primer was 5'CCATCACAACTAGGGTTTCCCA-3', while the antisense primer was 5'-TTAAGCTTGCGTTGCTCGTT TC-3' for PpAIV2. The actin gene was amplified using the following oligonucleotide primers as a control: sense 5'-ATGGTGAGGATATTCAACCC-3' and antisense 5'-CATGTCATCCCAGTTGCTCACTAT-3', based on the PPACT1 sequence.

\section{Results}

\section{Fruit assessment during storage}

The firmness of 'Gold Nijisseiki' flesh was $16.4 \mathrm{~N}$ at harvest (Fig. 1). The flesh firmness of fruit stored at $22^{\circ} \mathrm{C}$ decreased rapidly to $7.6 \mathrm{~N}$ at 28 days after harvest. Fruit stored at $0,4,10$, or $15^{\circ} \mathrm{C}$ demonstrated loss of firmness at 7 days after harvest, but was maintained at around $13 \mathrm{~N}$ even at 28 days after harvest. No significant differences were observed in firmness among fruit stored at $0,4,10$, or $15^{\circ} \mathrm{C}$ within the 28 days of storage considered in the present study.

Skin color at harvest was greenish, but fruit stored at 10,15 , or $22^{\circ} \mathrm{C}$ rapidly turned yellow within 14 days. However, cold storage, particularly at 0 or $4^{\circ} \mathrm{C}$, delayed these color changes, as evidenced by the changes in value of the hue angle (Fig. 2).

Total sugar content was hardly changed at all temper- 


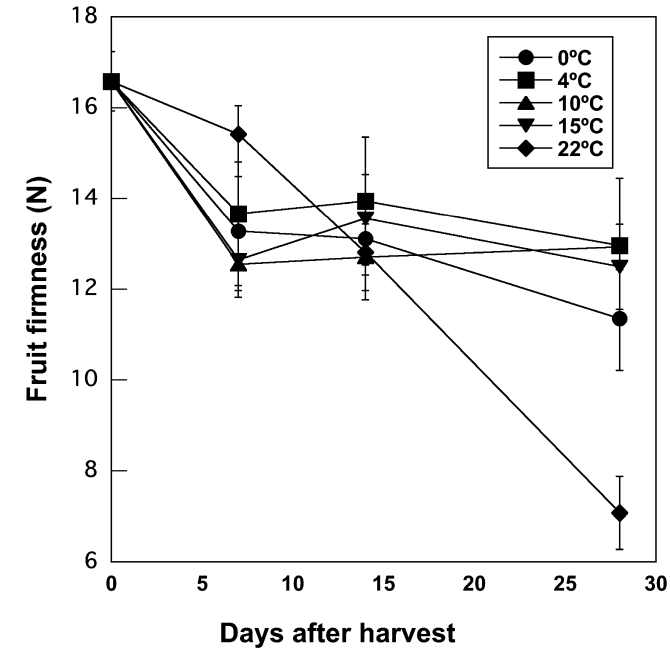

Fig. 1. Changes in flesh firmness of 'Gold Nijisseiki' pears stored at different temperatures $\left(0,4,10,15\right.$, or $\left.22^{\circ} \mathrm{C}\right)$. Vertical bars indicate the standard error from each mean value $(n=10)$.

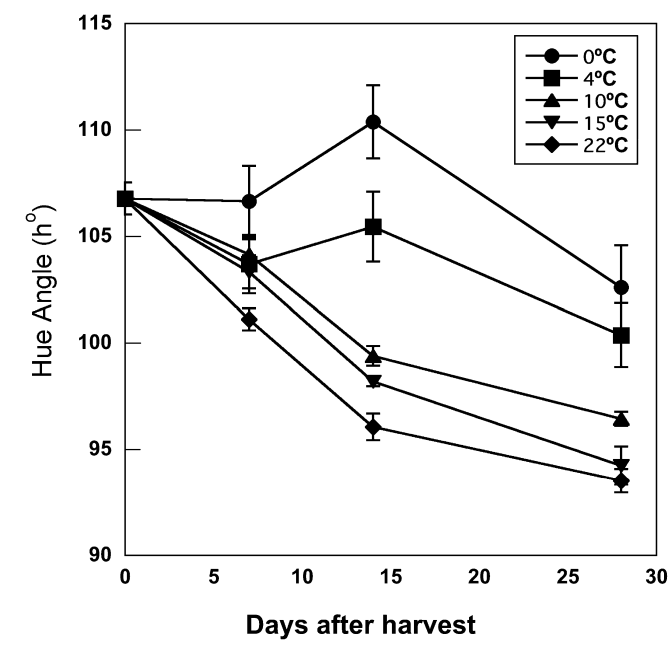

Fig. 2. Changes in skin color (hue angle) of 'Gold Nijisseiki' pears stored at different temperatures $\left(0,4,10,15\right.$, or $\left.22^{\circ} \mathrm{C}\right)$. Vertical bars indicate the standard error from each mean value $(n=10)$.

atures throughout the experiment (data not shown). Of the soluble sugars in the fruit, fructose and sucrose were predominant at harvest (Fig. 3). Sucrose content was maintained at all temperatures until 14 days after harvest, but decreased at 10,15 , or $22^{\circ} \mathrm{C}$ storage by 28 days after harvest. In particular, the sucrose content of fruit kept at 10 or $15^{\circ} \mathrm{C}$ decreased more rapidly than that of fruit stored at $22^{\circ} \mathrm{C}$. Fructose content increased in fruit stored at $15^{\circ} \mathrm{C}$ by 1 week after harvest, and the fructose content of fruit stored at 10,15 , or $22^{\circ} \mathrm{C}$ increased rapidly 28 days after harvest. Fructose content was highest in fruit stored at $15^{\circ} \mathrm{C}$. Glucose and sorbitol contents in fruit were lower than those of sucrose and fructose. Glucose content followed a similar trend to fructose content. Higher storage temperatures (10, 15, or $22^{\circ} \mathrm{C}$ ) resulted in higher glucose content 28 days after harvest. Colder storage treatments $\left(0\right.$ and $\left.4^{\circ} \mathrm{C}\right)$ resulted in little change in glucose content. However, colder storage $\left(0\right.$ and $\left.4^{\circ} \mathrm{C}\right)$ resulted in higher sorbitol content at 28 days after harvest.

\section{Expression of SPS and AIV during storage}

The expression profiles of PpSPS1, PpAIV1, and $P p A I V 2$ were investigated in fruit exposed to different storage temperatures using real-time RT-PCR (Fig. 4). The transcript levels of the genes were standardized relative to the constitutive expression level of the actin gene. PpSPS1 was expressed at nearly constant levels during the entire experimental period, except for 14 days after harvest and storage at $15^{\circ} \mathrm{C}$ (Fig. 4A). The level of PpAIV1 transcripts began to increase sharply after 14 days of storage at $0,10,15$, or $22^{\circ} \mathrm{C}$, reaching its maximum value at $10^{\circ} \mathrm{C}$ and then remaining constant until 28 days of storage at 10,15 , or $22^{\circ} \mathrm{C}$, whereas its expression of $0^{\circ} \mathrm{C}$ increased after 28 days after harvest (Fig. 4B). A delayed increase in the level of $P p A I V 1$ transcripts with $4^{\circ} \mathrm{C}$ storage was observed after 28 days after harvest. On the other hand, PpAIV 2 transcripts responded quickly to exposure to 10 or $15^{\circ} \mathrm{C}$ (Fig. $4 \mathrm{C}$ ). At $10^{\circ} \mathrm{C}$, the PpAIV2 mRNA increased rapidly and reached its maximum level within 7 days after harvest and then remained constant. Under the $15^{\circ} \mathrm{C}$ treatment, $P p A I V 2$ showed higher expression at 7 days after harvest, and then decreased again until 28 days. $P p A I V 2$ expression under the $22^{\circ} \mathrm{C}$ treatment remained at basal levels during the entire experimental period. In contrast, under cold storage $\left(0\right.$ or $\left.4^{\circ} \mathrm{C}\right)$, PpAIV 2 transcript accumulated and reached its maximum value at 28 days of $4^{\circ} \mathrm{C}$ storage.

\section{Discussion}

Pear fruit were stored at different temperatures $(0,4$, 10,15 , or $22^{\circ} \mathrm{C}$ ) for 28 days and then analyzed for the expression of genes for sucrose-metabolizing enzymes and for sugar levels. Softening proceeded more quickly in fruit stored at $22^{\circ} \mathrm{C}$. Low and moderate temperatures helped fruit retain firmness during a month in storage. However, skin colors changed more rapidly in fruit stored at temperatures of 10 to $22^{\circ} \mathrm{C}$. Color change is a major aspect of fruit ripening, along with softening. A delayed change in skin color was observed upon cold storage. In pear, as in other fruit species, cold storage slows the aging processes related to flavor, color, and texture.

Various studies have examined the effects of different storage temperatures on sugar content in other plant products (Ding et al., 1998; Huang et al., 1999). During storage at cold temperatures, potato tubers accumulate free reducing sugars derived from the breakdown of starch to sucrose, which is then converted into glucose and fructose (Blenkinsop et al., 2004; McKenzie et al., 2013; Samotus et al., 1974). This metabolic process is known as cold-induced sweetening (Sowokinos, 2001). Zrenner et al. (1996) reported that the soluble acid in- 
(A)

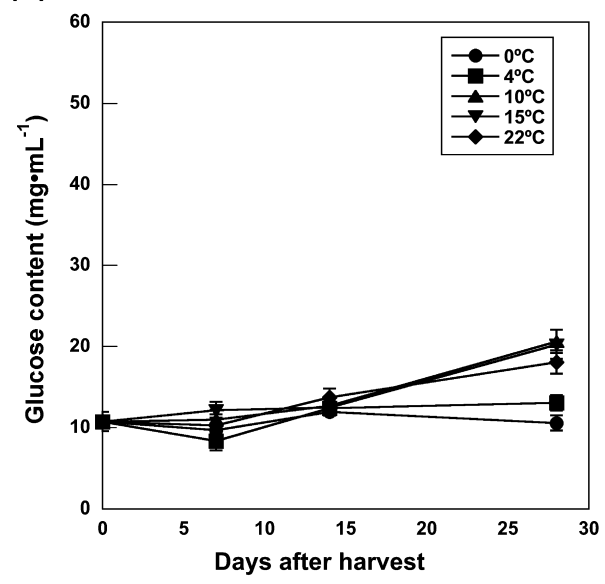

(B)

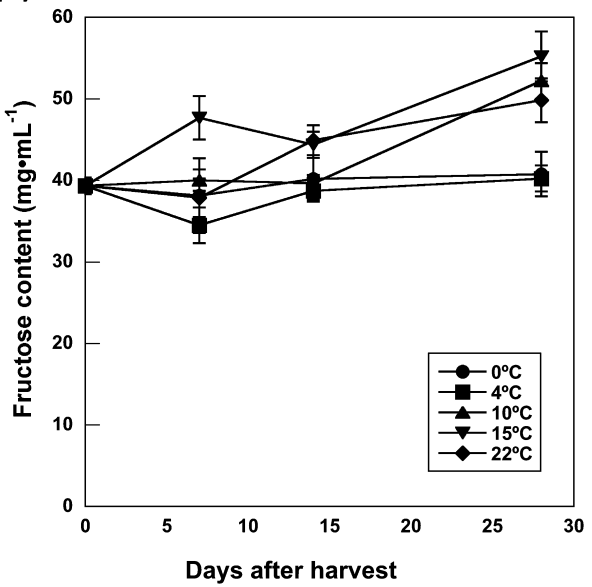

(C)

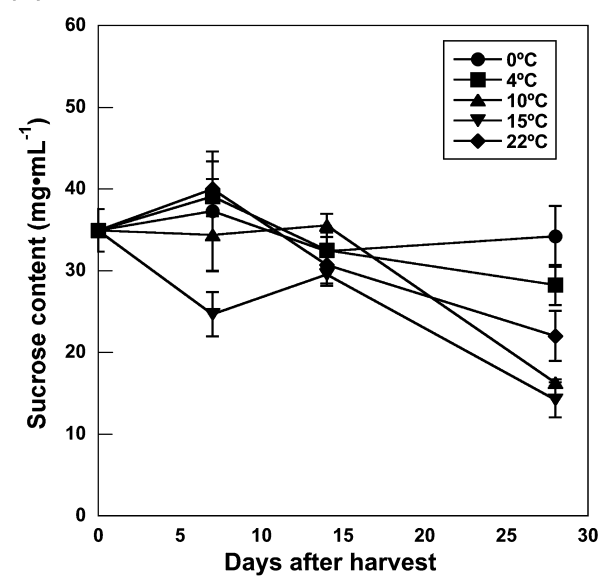

(D)

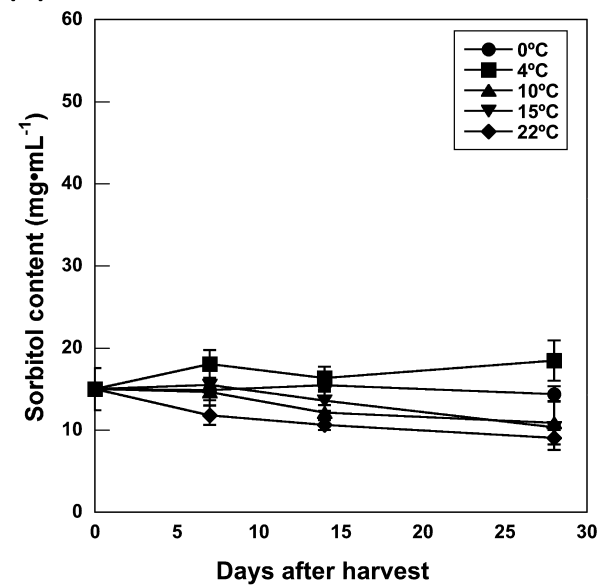

Fig. 3. Changes in total and individual sugar contents of 'Gold Nijisseiki' pears stored at different temperatures $\left(0,4,10,15\right.$, or $\left.22^{\circ} \mathrm{C}\right)$. (A) Glucose content, (B) fructose content, (C) sucrose content, (D) sorbitol content. Vertical bars indicate the standard error from each mean value $(\mathrm{n}=5)$.

vertase gene (INV19) is involved in the accumulation of reducing sugars during cold storage in potato tubers. We previously found the same cold-induced accumulation of reducing sugars in pear fruit (Itai and Tanahashi, 2008). Sucrose content was almost zero 1 month after $4^{\circ} \mathrm{C}$ storage in 'Gold Nijisseiki' and 2 months after $4^{\circ} \mathrm{C}$ storage in 'Hosui'. Fruit accumulate sugars in the vacuole, and sucrose in the vacuole is converted into hexose by vacuolar acid invertase. Additionally both neutral invertase and apoplastic acid invertase activities are significantly lower than that of vacuolar acid invertase and negligible in Japanese pear fruit (Yamada et al., 2006). Therefore, we cloned AIV (PpAIV1 and $P p A I V 2)$ and SPS (PpSPS1) from ripe pear fruit and examined their expression during storage (Itai and Tanahashi, 2008). The deduced amino acid sequences of PpAIV1 and PpAIV2 are almost identical to PsSAIV1 and PsS-AIV2, respectively, which are considered to be vacuolar acid invertases with a WECVD motif (Itai and Tanahashi, 2008; Yamada et al., 2007). The SPS and AIV constitute a multigene family (Ruan,
2014), so other isoforms should be clonable from other tissues. The expression of 2 vacuolar acid invertase genes was found to play an important role in sucrose degradation during cold storage. However, which specific temperatures had an influence on sucrose metabolism in pear fruit was unknown. Therefore, we studied the changes in the sucrose metabolism at 5 different storage temperatures.

Intermediate temperatures $\left(10\right.$ and $\left.15^{\circ} \mathrm{C}\right)$ induced higher expression of PpAIV2 at 1 week after harvest and of PpAIV1 at 14 days after harvest. Increased expression of these genes was followed by a decrease in sucrose and an increase in reducing sugar content at 28 days after harvest. There is a time lag between the changes in the levels of expression of the genes analyzed and the changes in the content of each sugar analyzed. The expression of $P p A I V 1$ was induced by $22^{\circ} \mathrm{C}$ treatment, whereas that of PpAIV2 was not. These data indicate that these 2 vacuolar acid invertase genes respond differently to temperature. Meanwhile, the expression of both PpAIV1 and PpAIV2 was increased at 
(A)

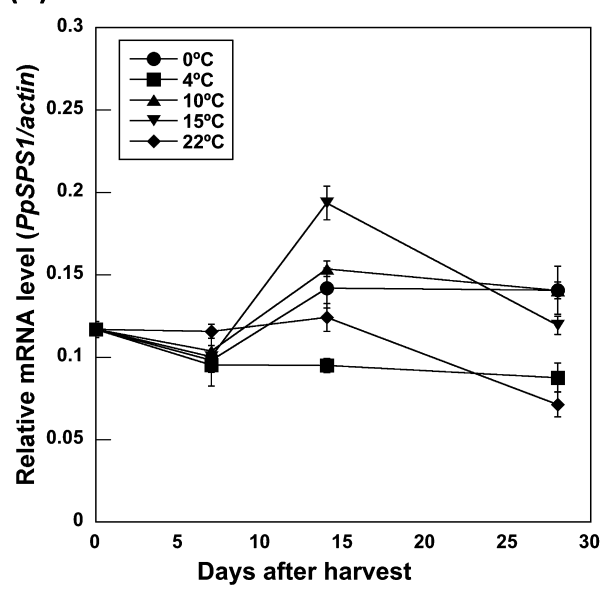

(B)

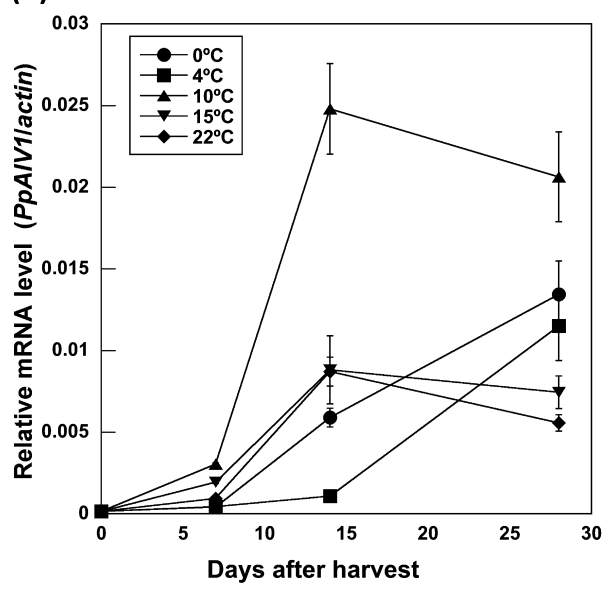

(C)

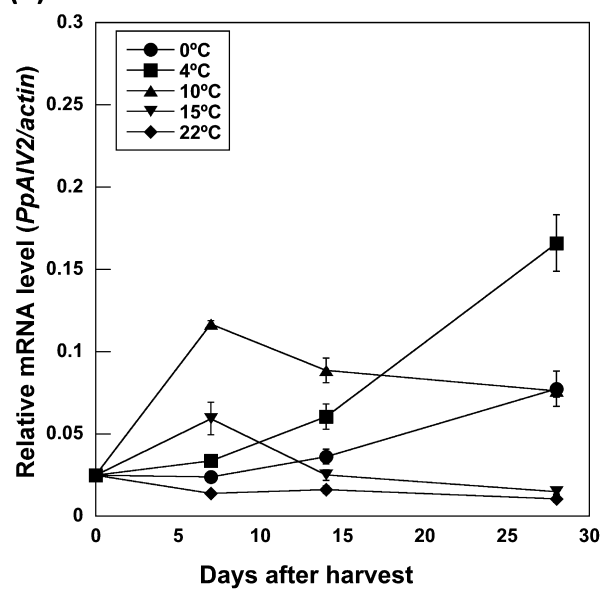

Fig. 4. Expression analysis of genes encoding sucrose phosphate synthase (PpSPS1) (A) and soluble acid invertases PpAIV1 (B) and PpAIV2 (C) in 'Gold Nijisseiki' fruit stored at different temperatures $\left(0,4,10,15\right.$, or $\left.22^{\circ} \mathrm{C}\right)$. Quantitative RT-PCR amplification of actin ( $\mathrm{PpACT1})$ was used to normalize the expression of each gene. Vertical bars indicate the standard error from each mean value ( 3 biological replications).

28 days after low-temperature treatment $\left(0\right.$ and $\left.4^{\circ} \mathrm{C}\right)$. In the present study, sucrose concentration was largely un- changed upon cold storage. Our previous study revealed that sucrose content had reached almost zero 1 month after $4^{\circ} \mathrm{C}$ storage in 'Gold Nijisseiki' (Itai and Tanahashi, 2008). It is unclear how the difference between the previous and present studies was generated. It may have resulted from annual variation in fruit physiological status. High levels of PpAIV1 and PpAIV2 expression on 28 days at $4^{\circ} \mathrm{C}$ storage would cause lower sucrose and higher reducing sugar content later. Yamada et al. (2007) investigated the relationship between the expression of 2 acid invertase genes and the enzyme activity throughout fruit development and found that the acid invertase activity seemed to correlate with the PsS-AIV1 transcript level during the developmental stages. It is not known whether the acid invertase activity was correlated with increased expression of 2 vacuolar invertase genes during storage. However, differences in the expression level of 2 vacuolar acid invertase genes between different temperatures appeared to be associated with reducing sugar accumulation. Villalobos-Acuna and Mitcham (2008) reported that exposure to intermediate temperature $\left(10^{\circ} \mathrm{C}\right)$ stimulated the capacity to produce adequate levels of ethylene during ripening more quickly than did exposure to low $\left(0^{\circ} \mathrm{C}\right)$ or high $\left(20^{\circ} \mathrm{C}\right)$ temperatures in 'Bartlett' pear. The results of the present and other studies indicate that ripened pear fruit may have differential sensitivity to low, intermediate, and high temperatures.

In our previous study (Itai and Tanahashi, 2008), we investigated the effect of two different temperatures $\left(4^{\circ} \mathrm{C}\right.$ and $\left.25^{\circ} \mathrm{C}\right)$ and 1-MCP treatment on the sucrose metabolism of stored fruit and suggested that PpAIVI could be responsible for sucrose degradation during storage in Japanese pear. In the present study, in addition to two different temperatures, we examined the effect of intermediate temperatures on sucrose metabolism during storage and suggested an important role for both PpAIV1 and PpAIV2 in sucrose degradation during storage. The effect of different temperatures on sucrose metabolism was variable in other species and tissues. The invertase transcript did not accumulate in potato tubers stored at $10^{\circ} \mathrm{C}$, but in tubers stored at $1{ }^{\circ} \mathrm{C}$, the invertase transcript level increased markedly within 7 days (Zhou et al., 1999). Invertase activities and reducing sugar concentration also significantly increased in roots of sweet potato kept at a low temperature (Huang et al., 1999). Sucrose loss was shown not to be increased by cold storage in loquat fruit (Ding et al., 1998), while sucrose content was largely unaffected during cold storage in apple (Ackermann et al., 1992). These reports provide evidence that sugar content during storage may be regulated by variability in the temperature-dependent expression of sucrosemetabolizing genes in various species.

In summary, storage temperature significantly influenced the expression of vacuolar acid invertase genes in fruit of Japanese pear. The expression of 2 vacuolar 
acid invertase genes had different responses to storage temperatures, especially at low $\left(0\right.$ and $\left.4^{\circ} \mathrm{C}\right)$ and intermediate temperatures $\left(10\right.$ and $\left.15^{\circ} \mathrm{C}\right)$.

\section{Literature Cited}

Ackermann, J., M. Fischer and R. Amado. 1992. Changes in sugars, acids, and amino acids during ripening and storage of apples (cv. Glockenapfel). J. Agric. Food Chem. 40: 11311134.

Beutel, J. A. 1990. Asian pears. p. 304-309. In: J. Janick and J. E. Simon (eds.). Advances in new crops. Timber Press, Portland, OR.

Bieleski, R. L. 1977. Accumulation of sorbitol and glucose by leaf slices of Rosaceae. Aust. J. Plant Physiol. 4: 11-24.

Blenkinsop, R. W., R. Y. Yada and A. G. Marangoni. 2004. Metabolic control of low-temperature sweetening in potato tubers during postharvest storage. Hort. Rev. 30: 317-354.

Ding, C.-K., K. Chachin, Y. Hamauzu, Y. Ueda and Y. Imahori. 1998. Effects of storage temperatures on physiology and quality of loquat fruit. Postharvest Biol. Technol. 14: 309 315.

Huang, Y. H., D. H. Picha, A. W. Kilili and C. E. Johnson. 1999. Changes in invertase activities and reducing sugar content in sweet potato stored at different temperatures. J. Agric. Food Chem. 47: 4927-4931.

Itai, A. and T. Tanahashi. 2008. Inhibition of sucrose loss during cold storage in Japanese pear (Pyrus pyrifolia Nakai) by 1-MCP. Postharvest Biol. Technol. 48: 355-363.

Kajiura, I., S. Yamaki, M. Omura, T. Akihama and Y. Machida. 1979. Improvement of sugar content and composition in fruits, and classification of East Asian pears by the principal component analysis of sugar compositions in fruits. Japan. J. Breed. 29: 1-12.

Ke, D., L. Rodriguez-Sinobas and A. A. Kader. 1991. Physiology and prediction of fruit tolerance to low-oxygen atmospheres. J. Amer. Soc. Hort. Sci. 116: 253-260.

Knee, M., N. E. Looney, S. G. S. Hatfield and S. M. Smith. 1983. Initiation of rapid ethylene synthesis by apple and pear fruits in relation to storage temperature. J. Exp. Bot. 34: 12071212.

Loescher, W. H. 1987. Physiology and metabolism of sugar alcohols in higher plants. Physiol. Plant. 70: 553-557.

McGuire, R. G. 1992. Reporting of objective color measurements. HortScience 27: 1254-1255.

McKenzie, M. J., R. K. Chen, J. C. Harris, M. J. Ashworth and D. A. Brummell. 2013. Post-translational regulation of acid invertase activity by vacuolar invertase inhibitor affects resistance to cold-induced sweetening of potato tubers. Plant Cell Environ. 36: 176-185.
Moriguchi, T., K. Abe, T. Sanada and S. Yamaki. 1992. Levels and role of sucrose synthase, sucrose-phosphate synthase, and acid invertase in sucrose accumulation in fruit of Asian pear. J. Amer. Soc. Hort. Sci. 117: 274-278.

Poritt, S. W. 1964. The effect of temperature on postharvest physiology and storage life of pears. Can. J. Plant Sci. 44: 568579.

Ruan, Y. L. 2014. Sucrose metabolism: Gateway to diverse carbon use and sugar signaling. Annu. Rev. Plant Physiol. 65: 33-67.

Samotus, B., M. Niedźwiedź, Z. Kolodziej, M. Leja and B. Czajkowska. 1974. Storage and reconditioning of tubers of Polish potato varieties and strains. I. Influence of storage temperature on sugar level in potato tubers of different varieties and strains. Potato Res. 17: 64-81.

Sowokinos, J. R. 2001. Biochemical and molecular control of cold-induced sweetening in potatoes. Amer. J. Potato Res. 78: 221-236.

Tanase, K. and S. Yamaki. 2000. Sucrose synthase isozymes related to sucrose accumulation during fruit development of Japanese pear (Pyrus pyrifolia Nakai). J. Japan. Soc. Hort. Sci. 69: 671-676

Villalobos-Acuna, M. and E. J. Mitcham. 2008. Ripening of European pears: The chilling dilemma. Postharvest Biol. Technol. 49: 187-200.

Wan, C. and T. A. Wilkins. 1994. A modified hot borate method significantly enhances the yield of high-quality RNA from cotton (Gossypium hiirsutum L.). Anal. Biochem. 233: 7-12.

Webb, K. L. and J. W. A. Burley. 1962. Sorbitol translocation in apples. Science 137: 766.

Yamada, K., T. Kojima, N. Bantog, T. Shimoda, H. Mori, K. Shiratake and S. Yamaki. 2007. Cloning of two isoforms of soluble acid invertase of Japanese pear and their expression during fruit development. J. Plant Physiol. 164: 746-755.

Yamada, K., Y. Suzue, S. Hatano, M. Tsukuda, Y. Kanayama, K. Shiratake and S. Yamaki. 2006. Changes in the activity and gene expression of sorbitol- and sucrose-related enzymes associated with development of 'La France' pear fruit. J. Japan. Soc. Hort. Sci. 75: 38-44.

Yamaki, S. and T. Moriguchi. 1989. Seasonal fluctuation of sorbitol related enzymes and invertase activities accompanying maturation of Japanese pear (Pyrus serotina Rehder var. culta Rehder) fruit. J. Japan. Soc. Hort. Sci. 57: 602-607.

Zhou, D., T. Solomos, H. Imaseki and A. K. Mattoo. 1999. Low temperature storage induces acid invertase in potato tubers (Solanum tuberosum). J. Plant Physiol. 154: 346-350.

Zrenner, R., K. Schuler and U. Sonnewald. 1996. Soluble acid invertase determines the hexose-to-sucrose ratio in cold-stored potato tubers. Planta 198: 246-252. 